\title{
Assessing mentalization in psychotherapy: first validation of the Mentalization Imbalances Scale
}

\author{
Giulia Gagliardini, ${ }^{1}$ Salvatore Gullo, ${ }^{2}$ Edgardo Caverzasi, ${ }^{3}$ Annalisa Boldrini, ${ }^{3}$ Stefano Blasi, ${ }^{1}$ Antonello Colli ${ }^{1}$ \\ ${ }^{1}$ Department of Humanities, "Carlo Bo" University of Urbino; ${ }^{2}$ Department of Psychology and Educational Sciences, University of \\ Palermo; ${ }^{3}$ Department of Brain and Behavioural Sciences, University of Pavia, Italy
}

\begin{abstract}
The aim of this study was to provide data on the preliminary validation of a clinician-report multidimensional assessment measure of mentalization (Mentalization Imbalances Scale, MIS). A random national sample of psychotherapists (N=190) completed the MIS to identify mentalization imbalances, and the Personality Disorder Checklist to assess the personality disorders (PDs) of randomly selected patients currently in their care. Factor analysis confirmed the presence of six factors that represented different imbalances of mentalization: cognitive, affective, automatic, external, imbalance toward others, and imbalance toward self. We found several significant relationships between patients' mentalization imbalances and personality pathology. Paranoid, schizoid, and schizotypal PDs were predicted by an imbalance toward self, an imbalance the patients shared with histrionic, avoidant, and obsessive compulsive PDs, whereas dependent, borderline, and histrionic PDs were related to an imbalance toward others. Cognitive imbalance was related to schizoid, narcissistic, and obsessive compulsive PDs, whereas affective imbalance predicted antisocial, borderline, narcissistic and histrionic PDs. Automatic imbalance was related to schizotypal, antisocial, and borderline PDs. MIS represents a reliable and valid measure that can help clinicians at understanding patients' specific diffi-

Correspondence: Giulia Gagliardini, Department of Humanities, culties of mentalization.
\end{abstract} "Carlo Bo" University of Urbino, via Saffi 15, 61029 Urbino, Italy. Tel.: +39.0722305833.

E-mail: giulia.gagliardini@uniurb.it

Citation: Gagliardini, G., Gullo, S., Caverzasi, E., Boldrini, A., Blasi, S., \& Colli, A. (2018). Assessing mentalization in psychotherapy: first validation of the Mentalization Imbalances Scale. Research in Psychotherapy: Psychopathology, Process and Outcome, 21(3), 164-177. doi: 10.4081/ripppo.2018.339

Contributions: all authors participated in the revision of the draft of this manuscript. GG and AC developed the research question and the methodology, actively participated in the collection of data, in data analysis and in the preparation of the manuscript. AB, EC, and SB actively participated in the data collection and in the revision of the manuscript. SG actively participated in data analysis and in the preparation of the manuscript.

Conflict of interest: the authors declare no potential conflict of interest.

Acknowledgements: the authors would like to thank all the clinicians who participated to this research project, for their time and willingness to contribute to the study.

Funding: this work was funded by the Society for Psychotherapy Research with the Small Research Grant Award.

Received for publication: 25 October 2018.

Revision received: 29 November 2018.

Accepted for publication: 5 December 2018

This work is licensed under a Creative Commons Attribution NonCommercial 4.0 License (CC BY-NC 4.0).

CCopyright Giulia Gagliardini et al., 2018

Licensee PAGEPress, Italy

Research in Psychotherapy:

Psychopathology, Process and Outcome 2018; 21:164-177

doi:10.4081/ripppo.2018.339
Key words: Mentalization; Personality disorders; Assessment.

\section{Introduction}

Since its introduction in psychological science, the construct of mentalization has been a subject of growing interest among various authors, especially in recent years (e.g., Bateman \& Fonagy, 2012; Choi-Kain \& Gunderson, 2008; Katznelson, 2014; Liljenfors \& Lundh, 2015). Mentalization failures are considered a core problem of personality disorders (PDs) (Antonsen, Johansen, Rø, Kvarstein, \& Wilberg, 2016; Bateman, Bolton, \& Fonagy, 2013), especially borderline PD (e.g., Petersen, Brakoulias, \& Langdon, 2016), and of different psychopathological domains (e.g., Rudden, Milrod, Target, Acherman, \& Graf, 2006; Skårderud, 2007; Taubner, Kessler, Buchheim, Kächele, \& Staun, 2011). In addition, treatments that address this key element have proved to be effective at significantly reducing symptomatology and increasing interpersonal functioning (Bateman \& Fonagy, 1999, $2008,2009)$. Despite the large number of important theoretical works done on this topic, the empirical literature on mentalization has been suffering from problems related to the assessment measures used in empirical research, which seem to be affected by the unclear definition of the construct and present some disadvantages that limit their large-scale use.

The theory of mentalization was proposed by Fonagy (1991) and developed by several authors over time, leading to an important, growing number of works and papers 
on the topic (see, for example, Bateman \& Fonagy, 2012; Choi-Kain \& Gunderson, 2008; Katznelson, 2014).

The activity of mentalizing has been defined in different ways (e.g., the capacity to "represent behavior in terms of mental states," Fonagy \& Target, 1997, p. 679; "the capacity to make use of an awareness of their own and other people's thoughts and feelings," Fonagy \& Target, 1998, p. 92; the "human tendency to look beyond the visible shell of the body in understanding behaviors and seeking descriptions and explanations in terms of states of mind," Fonagy, Bateman, \& Luyten, 2012, p. 3; etc.). Among the different definitions of the construct, one of the more exhaustive describes mentalization as "the mental process by which an individual implicitly and explicitly interprets the actions of himself and others as meaningful on the basis of intentional mental states such as personal desires, needs, feelings, beliefs, and reasons" (Bateman \& Fonagy, 2004, p. xxi). This definition is useful for empirical and clinical purposes because it distinguishes four different facets of mentalization: self, other, implicit, and explicit. The self and other facets are related to the the object of mentalizing, i.e. our own mental states or other people's inner states and experiences, while the implicit and explicit facets refer to the differentiation between automatic (implicit) processes of mentalizing and controlled (explicit) mentalization (Allen, Fonagy, \& Bateman, 2008).

A further development of the definition of this construct was introduced through the conceptualization of mentalization as the result of six different dimensions (Choi-Kain \& Gunderson, 2008): self, other, cognitive, affective, explicit, and implicit. This conceptualization was later enriched by Fonagy and Luyten (Fonagy et al., 2012; Luyten, Fonagy, Lowyck, \& Vermote, 2012), who described mentalization as composed by eight dimensions: automatic (implicit) mentalization, controlled (explicit) mentalization, mentalization toward self, mentalization toward others, cognitive mentalization, affective mentalization (sometimes also defined as "mentalized affectivity"; Jurist, 2005), internally focused mentalization, and externally based mentalization. The described facets can also be seen as interacting parts of multiple dimensions or polarities: For example, the affective domain of mentalization may be described as the side of polarity that is on the other end of the cognitive facet, whereas the self facet may represent the other side of the other domain (Fonagy et al., 2012). A good capacity to mentalize can be seen as the result of an equilibrium between the different dimensions of the construct, while problematics in mentalization may manifest throughout specific imbalances on one or more dimensions of the construct, since these dimensions typically represent systems in which a dysfunction at one end can be expressed as an excess at the other pole (Fonagy et al., 2012).

The automatic facet refers to the implicit and unconscious processes of recognizing and understanding inner mental states in oneself and others (for example, when one implicitly keeps another person's mind in one's mind during a conversation). Controlled mentalization, on the contrary, refers to a conscious and deliberate action, such as when we talk about our feelings or motivations (Allen et al., 2008).

The self and others dimension is related to the object of mentalization itself: Mentalization can, in fact, refer to the capacity to reflect on our own inner experiences, such as when we describe our emotions and/or feelings in a particular situation (the mentalizing toward self dimension), but it can also be focused on other people, such as when we are able to empathize with a friend who is having a hard time, or when we can understand the underlying reasons for other people's behaviors (mentalizing toward others). The self/others dimensions are in line with the descriptions that different authors have provided of abilities sometimes defined as self-awareness (Auerbach $\&$ Blatt, 1996) or self-reflexivity and other mind comprehension (Semerari et al., 2003).

The cognitive facet of mentalization refers to the activity of thinking about thinking and of understanding the representational nature of thoughts: It allows us to understand how one's interpretation of reality is subjective and is only one of infinite possibilities (Fonagy, Gergely, Jurist, \& Target, 2002). Affective mentalization is a particular type of affective regulation that is composed of three different domains (Jurist, 2005): identifying, processing, and expressing affective mental states. The distinction between cognitive and affective mentalization is in line with the theories that have suggested a distinction between a basic emotional contagion system and a more refined cognitive perspective-taking system (Shamay-Tsoory, Aharon-Peretz, \& Perry, 2009).

Emerging neuroscience data also indicate that these capacities may be related to distinct neuro-cognitive systems: Cognitively oriented mentalization involves the prefrontal cortex, whereas affective mentalization seems to be particularly related to the ventromedial prefrontal cortex, an area that is hypothesized to be involved in the activity of marking mental representations with affective information (Fonagy et al., 2012; Luyten \& Fonagy, 2015; Rochat \& Striano, 1999). Finally, mentalization can be focused either on the external manifestations of mental states (e.g., body posture, face expressions, etc.; externally focused mentalization) or on the inner worlds of individuals (e.g., beliefs, desires, etc.; internally focused mentalization; Fonagy et al., 2012).

At the core of this conceptualization is the idea that problematics in mentalization may manifest throughout specific imbalances in one or more dimensions of the construct. For example, an imbalance toward the self components of mentalization is typical of patients with excessive concern about their own mental states or behaviors but who lack in the capacity or willingness to reflect on other people's minds (Dimaggio et al., 2007). An imbalance toward others, on the contrary, may result in excessive con- 
cern about what other people think and feel, not paired with an adequate reflection on mental states related to the self (Fonagy \& Bateman, 2006), which may result in the tendency to be easily influenced by others. Moreover, an imbalance in the cognitive facets of mentalization seems to be characteristic of patients who tend to rely excessively on abstract thinking and to detach from emotions (e.g., patients with narcissistic PD; Blair, 2008; Blatt, 2008), whereas an imbalance in the affective dimension of mentalization implies problems related to the identification, processing, and expression of emotions (Jurist, 2005 ), in which the affects overcome the patient's capacity to think and to recognize the mental states underlying behaviors.

It is important to observe that while the cognitive/affective and the self/others dimensions of mentalization may be coherently described and defined from a theoretical and a clinical point of view, and can be seen as easily distinguishable dimensions of experience, this may not be so true for the controlled/automatic and external/internal dimensions of experience. It is, in fact, more difficult to conceptualize an imbalance on the internal dimension as a result of some form of deficit in the external polarity of mentalization; the same can be seen with the controlled/automatic dimension, since it is conceptually difficult to hypothesize an imbalance on the controlled dimension as a result of problematics in the automatic facets of mentalization. In terms of imbalances these dimensions seem to be not easily distinguishable.

Therefore we believe that, while it is quite easy to think about an affective imbalance as associated to difficulties in the cognitive facets of mentalization, and vice versa, the same is not true for the internal/external dimension. From a phenomenological and clinical perspective, in fact, we may conceptualize an imbalance on the external facet of mentalization (e.g. a patient who sees the therapist frowning and therefore hypothesizes that he or she is bored), it is more difficult to hypothesize that the patents overestimates the internal facets of mentalization without considering the external cues of mentalizing, and this is more true for cognitive processes. For example, whereas the differentiation internal/external seems easily applicable to emotions, which have both external expressions and internal feeling qualities, this does not seem to be the case with cognitions, which do not have bodily expressions to any similar degree (Liljenfors \& Lundh, 2015).

\section{Mentalization and psychopathology}

Different psychopathological domains, especially PDs, can be interpreted as an imbalance of one or more of the dimensions of mentalization (e.g., Bateman et al., 2013). Narcissistic PD, for example, seems to be related to the marked capacity to cognitively mentalize, which is, however, linked to a form of detachment from the affective aspects of one's experience (Blair, 2008; Blatt,
2008; Luyten et al., 2012) that suggests that these patients may show an imbalance in the cognitive dimension of mentalization and, as a consequence, a dysfunction in the affective pole. On the contrary, borderline and histrionic PDs seem to be linked to imbalances in the automatic and affective facets of mentalization (Blatt, 2008; Lowyk et al., 2016; Semerari et al., 2015).

Some authors have also suggested that antisocial PD is related to an over-involvement of the external facets of mentalization and to the incapacity to understand and empathize with other people's mental states (Bateman et al., 2013). This suggests that patients with antisocial PD may be characterized by an imbalance in the self dimension of mentalization and in automatic mentalization, which is related to the external cues rather than inner mental states. Similarly, patients with schizotypal PD tend to have difficulty reading other people's affects, especially negative emotions (Ripoll et al., 2013), which suggests that they may share an imbalance in the self dimension of mentalization.

Authors have also hypothesized that patients with dependent, obsessive-compulsive, and avoidant PDs (Cluster $C$ disorders, according to the DSM-IV-TR; American Psychiatric Association - APA, 2000), may share problems related to alexithymia, or difficulty focusing, identifying, and describing feelings (Lysaker et al., 2014), suggesting that they may be characterized by an imbalance in the cognitive dimension of mentalization. Moreover, dependent PD may be characterized by an imbalance in the others facet because among the core features of this disorder are the tendency to excessively rely on others for everyday decisions and the fear of loss and abandonment (APA, 2013).

From a clinical point of view, this conceptualization in terms of imbalances in mentalization implies that clinicians should focus during the sessions on the specific imbalances of the patients in order to counterbalance them: For example, a patient who will manifest a significant imbalance toward the others polarity of mentalization will suggest to the clinician the necessity to focus the therapeutic work on the opposite dimension of mentalization, that is, the self, in order to regulate the mental state of the patient.

To illustrate this point, we briefly report an interaction between a therapist and his patient diagnosed with borderline personality disorder and eating disorders from the verbatim transcript of a recorded therapeutic session:

Therapist: "How are you feeling?"

Patient: "My friends say that I am calmer."

T: "That's what your friends say, but I really want to know how you feel, not what someone else says."

P: "I don't know what I'm feeling... Maybe, maybe... I do not know, am I feeling bad? (starts crying)"

T: "For example, how do you feel while we talk, right now?"

P: "Now? I don't know."

In the reported interaction, the patient shows an im- 
balance toward others, as suggested by the fact that when asked "How are you feeling?," she answered by reporting other people's points of view and not her own. Recognizing this imbalance suggests to the therapist the need to counterbalance it by focusing on the opposite dimension, that is, the self of the patient.

\section{Assessing mentalization with different measures and from different perspectives}

Despite the promising and growing literature on this topic, an important gap still exists in our empirical knowledge of mentalization profiles in different clinical populations, which may also be related to some problematic issues in the assessment of the construct, considering that "many issues concerning the assessment of mentalization have not yet been solved" (Luyten et al., 2012 , p. 54). The most widely used assessment measure of mentalization is the Reflective Functioning Scale (RFS), a scale that is rated on the basis of the Adult Attachment Interview and that shows good psychometric properties: Inter-rater reliabilities vary from good to excellent in different studies (Fonagy et al., 1996; Fonagy, Steele, \& Steele, 1991).

The RFS represents an expert rating of mentalization that is useful for empirical purposes, but it can provide only a single, global score on a Likert scale from -1 (negative RF) to +9 (marked RF), which fails to encompass the rich and multidimensional domains of mentalization (Choi-Kain \& Gunderson, 2008; Gullestad \& Wilberg, 2011). In other words, the RFS provides an indication of the measure of a patient's RF but does not give us information on the areas or dimensions that are specifically problematic. Another measure, the Metacognition Assessment Scale (MAS) (Semerari et al., 2003), is based on therapy transcripts and overcomes the mono-dimensionality problems of the RFS by differentiating metacognitive processes in three dimensions: understanding one's own mind, understanding others' minds, and mastery. The first two dimensions are related to the ability to reflect upon the self and others' mental states, and the third dimension represents the capacity to regulate and control mental states.

Although the RFS and MAS have shown good reliability and validity, they are time consuming because they require, for the assessment, therapy session transcripts or interviews (e.g., Adult Attachment Interview or Metacognitive Assessment Interview) and long trainings in order to be applied in a reliable way. This restricts their application in large-scale studies that involve a wide sample of patients and limits their use in clinical contexts.

Another methodology used to assess mentalization is represented by self-report measures, such as the Reflective Functioning Questionnaire (RFQ) (Badoud et al., 2015;
Fonagy et al., 2016; Ha, Sharp, Ensink, \& Cirino, 2013) or the Mentalization Questionnaire (MZQ) (Hausberg et al., 2012). The RFQ is a self-report questionnaire composed of eight items rated on a Likert scale from 1 (completely disagree) to 7 (completely agree). It refers to two different scales: excessive certainty about mental states, which reflects hypermentalizing as assessed by the level to which the patient disagrees with items such as "I don't always know what I do," and excessive uncertainty about mental states, which reflects hypomentalizing and a lack of knowledge on mental states, as assessed by items such as "Sometimes I do things without really knowing why." Each scale is composed of six items, with four items loading into both of the scales of the RFQ. The factor structure of the RFQ has been investigated in different preliminary studies, including a confirmatory factor analysis, with the model showing a good fit $\left(\chi^{2} \mathrm{df}=2.2\right.$; Root Mean Square Error of Approximation, RMSEA $=0.06 ; \quad$ CI $[0.04,0.07]$; Comparative Fit Index, $\mathrm{CFI}=0.95, \mathrm{NNFI}=0.93$; Fonagy et al., 2016).

The MZQ is a multi-dimensional self-report measure of mentalization composed of 15 items. Hausberg et al. (2012) used the MZQ with a sample of 97 patients, and by applying a principal component analysis with varimax rotation, they found four different dimensions that explained $59 \%$ of the variance: i) refusing self-reflection (four items, alpha .68), comprising the avoidance of thinking about inner states, or a systematic rejection of one's own feelings combined with the fear of being overwhelmed by them; ii) emotional awareness (four items, alpha .68), which refers to a lack of perceiving and differentiating one's own inner states; iii) the psychic equivalence mode (four items, alpha .57), which refers to the pre-mentalizing modality of thought in which inner mental states and outer reality are equated and everything appears real, which is related to an unstable inner representation of relations and a lack of flexibility; and iv) the regulation of affect (three items, alpha .60), comprising the inability to modulate affect, which can produce feelings of helplessness and make people feel threatened by their own feelings. This four-factor structure was also investigated with confirmatory factor analysis on a different sample of inpatients, indicating a satisfactory goodness of fit of the model (global fit index of .90; root mean square error of approximation of .065; standardized root mean residual of .063; Hausberg et al., 2012).

Self-report assessment tools have the important advantage of being less time consuming and easier to use, but they can be problematic in terms of being filled out in a reliable way by patients with PDs, who are characterized by impairments in self-reflexivity and egosyntonic traits. In addition, most of the measures that assess mentalization and overlapping constructs mostly assess controlled mentalization, and, in general, they asses mentalization offline and not during social interactions (Luyten et al., 2012). 
Previous studies have, on the contrary, suggested that clinicians tend to make highly reliable evaluations if their observations and inferences are quantified using psychometrically sophisticated instruments (Blagov, Bi, Shedler, \& Westen, 2012; Westen \& Weinberger, 2004). The assessment of mentalization from a therapist perspective has two main advantages: i) Clinicians can also evaluate implicit and automatic mentalization by observing how their patients interact with them, and ii) considering that the therapeutic relationship tends to activate the attachment system and stress mentalizing capacities (Allen et al., 2008), clinicians can also evaluate mentalization in the here and now of the interaction with the patient (online mentalization).

\section{Aims of the present study}

The main goals of this study were to present a new clinician report measure for the assessment of mentalization imbalances in clinical practice and to provide data on the first step in the validation of the measure.

The aims of the present study were to:

i) Describe the development of a new assessment measure of mentalization, the Mentalization Imbalances Scale (MIS), and provide initial data on the reliability and factor structure of the MIS.

ii) Examine the criterion validity of the scale by investigating the relationship between the factors of mentalization and personality pathology.

iii) In the present study, confirmatory factor analysis was used because there was some knowledge of the underlying latent variable structure based on previous research. The goal of this model-testing procedure is: i) The residual refers to the difference between the model and the data. ii) Fit statistics reflect the amounts of variance and covariance in the data that are accounted for by the model vs. the residual. iii) Goodness of fit indices provide a way to evaluate how well the hypothetical model agrees with the empirical data.

We expected to find six different imbalances, related to the construct of mentalization: cognitive, affective, self, others, external, and automatic.

Second, we expected that different PDs would be characterized by specific imbalances and more specifically that:

i) A cognitive imbalance would be related to narcissistic, obsessive-compulsive, and schizoid PDs;

ii) An affective imbalance would be found in borderline and histrionic PDs;

iii) An imbalance toward self would be related to narcissistic and antisocial PDs;

iv) An imbalance toward others would be present in borderline and dependent PDs;

v) An automatic and external imbalance would be related to borderline PD.

\section{Materials and Methods}

\section{Development of the Mentalization Imbalances Scale}

The Mentalization Imbalances Scale is a clinician-report measure for the assessment of the mentalization imbalances. In order to develop the assessment measure and to operationalize mentalization we adopted the definition of mentalization as the mental process "by which an individual implicitly and explicitly interprets the actions of himself and others as meaningful on the basis of intentional mental states such as personal desires, needs, feelings, beliefs, and reasons" (Bateman \& Fonagy, 2004, p. $\mathrm{xxi}$ ); We used this definition in order to create a list of items related to imbalances in the aforementioned dimensions of the construct. The first set of items was derived by reviewing the clinical, theoretical, and empirical literature on mentalization and related variables (e.g., metacognition, theory of mind, empathy, etc.) and by reviewing the most widely used assessment measures of mentalization and related constructs. In light of the aforementioned observations related to the dimensions of the constructs, the first pool of items was generated by considering six different facets of mentalization: self, other, cognitive, affective, external, and automatic (Table 1).

This first set of items was evaluated using a 5-point Likert scale in terms of clarity and face validity by a pool of 10 clinicians experienced in the treatment of patients with PDs and in the concept of mentalization. The participants rated items' relevance from 1 (not relevant) to 4 (very relevant) and their clarity from 1 (not clear) to 4 (very clear). A content validity index (Yaghmaie, 2009) was calculated by identifying the percentage of experts who rated an item as being both relevant and clear. Items that had a content validity index over 0.75 remained, and the rest were discarded; the remaining 49 items were modified based on the experts' suggestions. This led to the first version of the scale, which was sent to a pool of 50 clinicians; each used it to rate a selected patient who met our inclusion criteria (each patient had to be at least 18 years old, have had no psychotic disease or psychotic symptoms in the previous six months, and have a PD or clinically relevant problem related to personality). We used clinicians' evaluations to conduct a preliminary descriptive item analysis, and we eliminated items with values of skewness and kurtosis \pm 2 , items with a mean equal to 0 or to 5 and zero variances, and items that did not correlate with any other item. The final item list contained 27 items; each item is rated by clinicians on a Likert scale from 0 (not descriptive) to 5 (absolutely descriptive).

\section{Sampling procedure}

From the rosters of the two largest Italian associations of psychodynamic and cognitive-behavioral psychotherapy, and from centers specialized in the treatment of PDs, we recruited, by e-mail, a random sample of clinicians with at 
least three years of post-psychotherapy licensure experience. We requested that they each select a patient who was at least 18 years old, who had had no psychotic disorder or psychotic symptoms for at least the previous six months, whom the therapist had seen for a minimum of six sessions and a maximum of 18 months, and who had a PD diagnosis or clinically relevant personality problem. We asked clinicians to rate a patient whom they had seen at least four times before doing the assessment, and to assess the selected patient considering the way he or she has behaved in the last month. We asked clinicians to use different assessment measures for assessing a patient's mental functioning and, in doing so, to use both the explicit contents and narratives and the way in which the patient procedurally interacted with the therapist in the course of the last six sessions. To minimize selection biases, we directed clinicians to consult their calendars to select the last patient each had seen during the previous week who met the study criteria. To minimize rater-dependent biases, each clinician was allowed to describe only one patient. We contacted 980 clinicians, of whom $260(26.5 \%)$ responded that they were willing to participate. Of these, $236(24.1 \%)$ indicated they were currently treating a patient who met the inclusion criteria and were invited to participate, and 190 returned completed measures, for an overall response rate of $19.4 \%$. Clinicians received no remuneration. All participants provided written informed consent.

\section{Patients}

The sample consisted of 190 Caucasian patients, including 66 (35\%) men and 124 (65\%) women. Their mean age was 34 years $(S D=11.3$, range 18-65). The average length of treatment was 13 months $(S D=10.6$; range 1-
18). Twenty-six patients (14\%) had had one previous hospitalization, and $38(20 \%)$ had had two or more. Fortyone patients $(22 \%)$ had previously attempted suicide, and 101 patients $(53 \%)$ were also taking some form of pharmacotherapy. One hundred and eleven patients (62\%) had a diagnosis of personality disorder, alone or in comorbidity, following DSM-5 criteria, and 78 patients (41\%) had clinically relevant personality problems. One hundred and eighty-five patients had one or more other DSM-5 diagnoses: The most common diagnoses were mood disorders $(N=120)$, anxiety disorders $(N=96)$, and substance-related and addictive disorders $(N=57)$.

\section{Therapists}

This sample consisted of 190 Caucasian therapists, including $76(40 \%)$ women and $114(60 \%)$ men. Their mean age was 39 years $(S D=10.9$; range 27-68). Three main theoretical approaches were represented: psychodynamic $(N=80)$, cognitive-behavioral $(N=57)$, and mentalizationbased treatment $(N=43)$; ten therapists reported other theoretical orientations (i.e., eclectic, systemic, integrated). The average length of clinical experience as a psychotherapist was 10 years $(S D=10.1$; range 3-35). Seventy-four $(39 \%)$ therapists were seeing the selected patient in private clinical practice, while $116(61 \%)$ were working in public mental health.

\section{Measures}

We employed a number of measures in standardized sequence. We describe those of relevance to the present study here.

The 34 items of the MIS were described in the previous

Table 1. Facets considered in the construction of the Mentalization Imbalances Scale's First Set of Items.

Self An imbalance toward self indicates excessive involvement in the description and knowledge of self mental states (Allen, Fonagy, \& Bateman, 2008), which can be paired with the inability to assume other people's perspectives and to consider points of view that differ from our own (Dimaggio et al., 2007). This can manifest through an excessive certainty about other people's mental states and through a lack of curiosity about mental states different form our own.

Others An imbalance toward others indicates the tendency to focus on other people's mental states (Fonagy, Bateman, \& Luyten, 2012) rather than on our own. This can manifest through the tendency to imitate other people or to be easily influenced by others, as a person is excessively focused on other people's experiences (rather than on his/her own).

Cognitive An imbalance in this dimension of mentalization is characterized by a sort of detachment from the affective experience, with the excessive manifestation of abstract reasoning or thought (Allen et al., 2008). This can be related to the inhibition of emotions.

Affective An imbalance in this dimension indicates excessive emphasis on the emotions, which is not paired with an adequate capacity to explicitly and cognitively reflect on mental states. This can lead to impulsive actions, as emotions tend to overcome the capacity to think: A good capacity to affectively mentalize implies, in fact, that a person identifies, processes, and expresses affects (Jurist, 2005). When this capacity is lacking, people tend to act when they experience intense emotions.

External An imbalance in the externally focused dimension of mentalization indicates those cases in which a person excessively relies on the external signs of mental states (i.e., facial expressions, body postures, etc.) and not on inner mental states (e.g., beliefs, desires, thoughts, emotions) (Luyten \& Fonagy, 2015).

Automatic An imbalance in this domain indicates the capacity to implicitly read and interpret people's facial expressions or any non-verbal cues related to mental states. It is the ability to recognize on a pre-verbal level other people's mental states, which, however, may not be paired with the capacity to explicitly and declaratively reflect on mental states, even when actively solicited to do so by someone (e.g., a therapist) (Fonagy et al., 2012). 
sections. The items of the MIS must be rated by a clinician who has met the selected patient at least four times before the assessment. The scale assesses the mental functioning and behaviors that the patient has manifested in the last month with the clinician. The items were answered by participants using a 6-point Likert scale from 0 (not descriptive) to 5 (highly descriptive). The items measure several imbalances in relation to different dimensions of mentalization: imbalance toward self (e.g., "P. doesn't seem capable of assuming other people's points of view when interpreting other people's behavior"), imbalance toward others (e.g., "P. can easily be influenced by other people's emotions"), affective imbalance (e.g., "When experiencing an intense emotion, P. can think clearly"), automatic imbalance (e.g., "P. fails to reflect on the first impression he or she has of a person or a situation"), and cognitive imbalance (e.g., "Even when talking about painful and/or emotionally intense themes, P. seems to be detached").

\section{Clinical questionnaire}

We constructed an ad hoc questionnaire for clinicians to provide general information about themselves, their patients, and the therapies they used. Clinicians provided basic demographic and professional data, including their disciplines (psychiatry or psychology), theoretical approaches, hours of work, number of patients in treatment, and gender, as well as patients' age, gender, other concomitant therapies (e.g., pharmacotherapy), and DSM-5 diagnoses (APA, 2013). Clinicians also provided data on their therapies, such as the length of treatment and number of sessions. Clinicians also assessed variables potentially related to etiology, such as the history of abuse and/or maltreatment. To provide a more comprehensive assessment of personality pathology and patients' problems, respondents rated the presence or absence of a list of clinical problems and personality characteristics, such as dissociative symptoms, self-harming behaviors, problems with intimacy or commitment in close relationships, difficulty with assertiveness or the expression of anger, and authority problems.

\section{Personality disorder}

We asked clinicians to rate each criterion, randomly ordered, for each of the DSM-5 personality disorder diagnoses (APA, 2013) as present or absent. This procedure provided both a categorical diagnosis (by applying DSM5 cutoffs) and a dimensional measure (number of criteria met for each disorder); in previous studies, this procedure proved adequate in terms of internal consistency and convergent validity (Betan, Heim, Zittel-Conklin, \& Westen, 2005; Blais \& Norman, 1997; Bradley, Heim, \& Westen, 2005; Westen, Shedler, Durrett, Glass, \& Martens, 2003).

\section{Statistical analysis}

Descriptive statistics (mean and standard deviations) were examined. Confirmatory Factor Analysis was performed to determine the goodness of fit between the sample data and the hypothesized MIS six-factors model by using maximum likelihood estimator. The following conventional fit indices were used to evaluate the overall model goodness model fit: Chi-square goodness-of-fit, ratio $\chi 2 / \mathrm{df}$ (ratios $<3$ indicate reasonable fit), Adjusted Goodness of Fit Index (AGFI), Tucker-Lewis fit index (TLI) and CFI. According to Hu \& Bentler's suggestion (1995) a criterion of .95 or above was used to describe a good fit and the .90 to .95 range for a adequate fit. For RMSEA, a value less than 0.08 was considered as reasonable model fit (Stevens, 2002). Finally, AGFI was calculated and values greater than 0.80 indicate an adequate fit (Kline, 1991). Significant standardized regression weights (standardized loading factor) indicates that the items are representative of their latent factor, whereas significant estimates of correlations indicates significant two-way correlation between factors. Model re-specification procedure was used following iterative process as outlined by Byrne (2001). We first systematically identified and excluded items with factor loadings on to the intended factor which were not statistically significant, and then recalculated fit statistics for the entire model after each change. Subsequently, Modification Indices were used to add item errors covariance when there was theoretical support for doing so. Reliability analysis was done to determine the reliability of the questionnaire. Internal consistency of the items was measured by using Cronbach's alpha coefficient (Cronbach, 1951). Composite Reliability (CR) and Average Variance Extracted (AVE) were calculated by computing formulas provided by Fornell and Larcker (1981). Considering that scores on PD domains were discrete count data (number of criteria met) Possion regression analysis was used to study the association between MIS and PD. The analyses were performed using AMOS software version 21 and PASW software version 22 .

\section{Results}

\section{Factor structure of the Mentalization Imbalances Scale}

The initial six-factor model with 27 items (i.e. cognitive imbalance represented by P22, P23, P24, P25 and P26; affective imbalance represented by P27, P29, P31 and P32; imbalance toward others represented by P17, P18, P19, P20 and P21; automatic imbalance represented by P5, P39, P47, P48 and P49; imbalance toward Self represented by $\mathrm{P} 6, \mathrm{P} 7, \mathrm{P} 13$ and $\mathrm{P} 15$; and external imbalance represented by P33, P36, P37 and P40) revealed a poor fit with the latent constructs $\left(\mathrm{X}^{2}(\mathrm{df})=838.77\right.$ (318), $\mathrm{P}<0.001$, ratio $\mathrm{X}^{2} / \mathrm{df}=2.63$, AGFI $=0.692$, TLI $=0.756$, $\mathrm{CFI}=0.779$, RMSEA $=0.094$ ), indicating needs for further modification. Based on the M.I. suggestions, five items (i.e. $\mathrm{P} 20, \mathrm{P} 21, \mathrm{P} 39, \mathrm{P} 48$ and $\mathrm{P} 40$ ) were removed from the initial model given their non significant loadings on intended factor. Six error covariances were added to the 
model when both the items load onto the same latent factor (P23-P25, P6-P7, P27-P29) or onto two polarized latent factors (P24-P29), and when covariance made theoretical sense (P15-P27, P27-P49).

The new six-factor model with 22 items showed a good fit with the latent constructs $\left(X^{2}(d f)=356.05\right.$ (197), $\mathrm{P}<0.001$, ratio $\mathrm{X}^{2} / \mathrm{df}=1.81$, AGFI $=0.809$, TLI $=0.904$, $\mathrm{CFI}=0.918$, $\mathrm{RMSEA}=0.066)$ and was considered as the final model for the MIS (Figure 1). Figure 1 shows the standardized regression weights of each items on the respective factor and the significant correlations between factors. As predicted, cognitive and affective imbalance factors were significantly negatively correlated (-.44; $\mathrm{P}<.001)$, affective imbalance was also positively corre- lated with both imbalance toward Self and toward others (.40 and .33, respectively; $\mathrm{P}_{s}<.001$ ), whereas cognitive imbalance was positively associated with automatic imbalance $(.43 ; \mathrm{P}<.001)$. Positive correlations were also found between external and toward others imbalance (.38; $\mathrm{P}<.001$ ), and between automatic and toward Self imbalance (.66; $\mathrm{P}<.001)$. Correlations between corresponding MIS subscales were instead presented in Table 2.

\section{Psychometric properties}

Descriptive, reliability and convergent validity are shown in Table 3. Reliability analysis showed that the Cronbach's alpha values ranged from .70 to .89 which in-

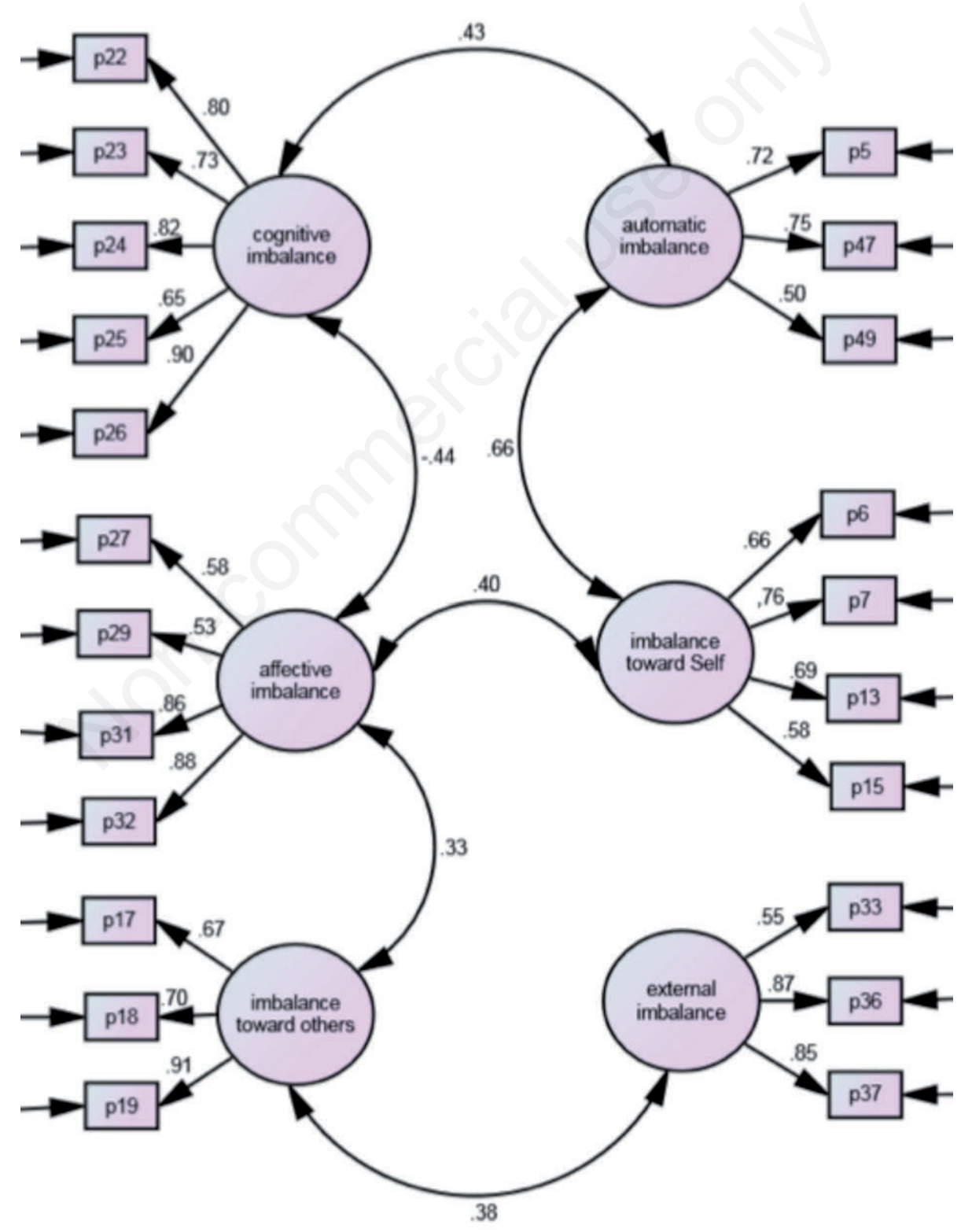

Figure 1. Standardized factor loadings of the final six-factor model of the MIS (all factor loadings and correlations are significant at .001 level). 
dicates a adequate to high level of internal consistency. The AVE values of Cognitive, Affective, External and toward Others Imbalance factors were more than .50 indicating adequate convergent validity, however the Automatic and toward Self Imbalance factors failed to demonstrate adequate convergent validity as its AVE value was less than .50 . The $\mathrm{CR}$ values for all the six factors of MIS were more than .70 indicated that they had good construct reliability (Fornell \& Larcker, 1981).

\section{Mentalization and personality disorders}

The second aim of our study was to assess the relationship between PDs and specific mentalization polarities to investigate the criterion validity of the MIS in relation to PDs. To do so, we applied a Poisson regression analysis and calculated which factor(s) of the MIS predicted the number of criteria for each PD (Table 4).

As shown in Table 4, all PDs had an association with one or more mentalization imbalances related to the aforementioned dimensions. The results show that paranoid, schizoid, and schizotypal PDs were predicted by an imbalance toward self, an imbalance they shared with histrionic, dependent, avoidant, and obsessive-compulsive PDs. Dependent, borderline, and histrionic PDs were, on the contrary, positively predicted by an imbalance toward others, while paranoid, schizoid, schizotypal and narcissistic PDs were negatively predicted by this specific imbalance. Cognitive imbalance predicted schizoid, narcissistic, and obsessive-compulsive PDs, whereas affective imbalance positively predicted antisocial, borderline, histrionic and narcissistic PDs and, negatively, schizoid and avoidant PDs. Automatic imbalance predicted borderline, antisocial, schizotypal, and avoidant PDs.

\section{Discussion}

The first aim of our work was to investigate the factor structure of a new clinician report assessment measure of mentalization imbalances. The results confirmed the presence of six mentalization imbalance factors that showed satisfactory reliability: cognitive imbalance, affective imbalance, imbalance toward others, automatic imbalance, imbalance toward self and external imbalance. Correlations among these factors are significant and coherent with the theory of mentalization (Table 2). These factors, which reflect different mentalizing imbalances, are theoretically coherent and seem to confirm that mentalization is composed of several dimensions, as some authors have suggested (e.g., Choi-Kain \& Gunderson, 2008; Fonagy et al., 2012; Fonagy, Luyten \& Bateman, 2015; Luyten et al., 2012).

Table 2. Correlations of Mentalization Imbalances Scale subscales.

\begin{tabular}{|c|c|c|c|c|c|c|}
\hline & Cognitive & Affective & Others & Self & Automatic & External \\
\hline Cognitive & - & $-.346 * *$ & -.069 & -.035 & .130 & -.046 \\
\hline Affective & - & - & $.371 * *$ & $.310 * *$ & .141 & .130 \\
\hline Others & - & - & - & -.114 & -.069 & $.318 * *$ \\
\hline Self & - & - & - & - & $.638 * *$ & -.084 \\
\hline Automatic & - & - & - & - & - & $.175^{*}$ \\
\hline External & - & - & - & - & - & - \\
\hline
\end{tabular}

$* \mathrm{P} \leq 0.05 ; * * \mathrm{P} \leq 0.01$.

Table 3. Descriptive, reliability and discriminate validity of Mentalization Imbalances Scale subscales.

\begin{tabular}{|c|c|c|c|c|c|c|}
\hline & Mean & SD & Cronbach's alpha & $\begin{array}{l}\text { Inter-item } \\
\text { correlations }\end{array}$ & $\begin{array}{c}\text { Average } \\
\text { Variance } \\
\text { Extracted }\end{array}$ & $\begin{array}{l}\text { Composite } \\
\text { Reliability }\end{array}$ \\
\hline Cognitive & 2.75 & 1.34 & .89 & .63 & .62 & .89 \\
\hline Affective & 2.98 & 1.28 & .83 & .55 & .54 & .81 \\
\hline Others & 2.25 & 1.23 & .81 & .59 & .59 & .81 \\
\hline Self & 3.26 & 0.87 & .78 & .47 & .45 & .75 \\
\hline Automatic & 3.09 & 0.93 & .70 & .43 & .45 & .70 \\
\hline External & 2.04 & 1.12 & .78 & .56 & .59 & .81 \\
\hline
\end{tabular}

SD, standard deviation. 
The factors are also coherent with different facets of mentalization assessed and described by other measures for the assessment of mentalization. An imbalance toward self and others may, in fact, be seen as a failure related to understanding one's own mind and understanding others' minds, as assessed by the MAS (Carcione et al., 2009). Moreover affective imbalance, which is composed of items describing a difficulty with processing and regulating emotions that may lead to impulsive behaviors, may share some common features with the regulation of affects scale of the MZQ (Hausberg et al., 2012). The automatic imbalance factor, which describes the difficulty of the patient in assuming, in relation to the self and others, an explicit mentalizing position that requires "reflection, attention, awareness, and effort" (Fonagy et al., 2012, p. 20), seems to describe a mentalization failure similar to the refusing self-reflection scale of the MZQ and a refusal of the patient to mentalize in relation to demand questions, as described in the RFS coding manual (Taubner et al., 2013).
The second aim of our research was to examine the relationship between mentalization imbalances and personality pathology. The associations that emerged seem to be in line with the clinical and theoretical literature (Table 4). All PDs are characterized by at least one imbalance in mentalization, thus confirming the assumption that problems in mentalization are a core problem in PDs (Bateman \& Fonagy, 2010; Dimaggio et al., 2007; Moroni et al., 2016; Semerari et al., 2014).

Borderline PD, for example, manifests a pattern characterized by an imbalance in the affective facets of mentalization, as well as an imbalance toward others and in automatic mentalization. Narcissistic PD, on the contrary, is characterized by the excessive involvement of the cognitive facets of mentalization and by a focus on the self and, contrarily to our expectations, on the affective facets of mentalization. This result may be related to the fact that we are basing our research on the DSM-5 codification of PDs, which does not distinguish between the different facets of narcissism, for example the overt and covert

Table 4. Poisson regression model of Mentalization Imbalances Scale factors predicting personality disorders.

\begin{tabular}{|c|c|c|c|c|c|c|c|}
\hline & $\mathbf{T}$ & SE & Wald $X^{2}$ & & $\mathbf{T}$ & SE & Wald X $X^{2}$ \\
\hline \multicolumn{4}{|l|}{ Paranoid } & \multicolumn{4}{|l|}{ Histrionic } \\
\hline Cognitive & .029 & .0617 & .217 & Cognitive & .100 & .0542 & 3.406 \\
\hline Affective & .109 & .0735 & 2.206 & Affective & .330 & .0730 & $20.510 * * *$ \\
\hline Others & -.175 & .0745 & $5.543 *$ & Others & .142 & .0625 & $5.154 *$ \\
\hline Self & .599 & .1349 & $19.685 * * *$ & Self & .258 & .1102 & $5.474^{*}$ \\
\hline Automatic & .063 & .1200 & .272 & Automatic & -.104 & .1022 & 1.027 \\
\hline External & -.010 & .0749 & .018 & External & .097 & .0614 & 2.471 \\
\hline \multicolumn{4}{|l|}{ Schizoid } & \multicolumn{4}{|l|}{ Narcisistic } \\
\hline Cognitive & .125 & .0611 & $4.224^{*}$ & Cognitive & .203 & .0588 & $11.876^{* * *}$ \\
\hline Affective & -.174 & .0635 & $7.502 * *$ & Affective & .242 & .0660 & $13.430 * * *$ \\
\hline Others & -.266 & .0720 & $13.644 * * *$ & Others & -.279 & .0671 & $17.297 * * *$ \\
\hline Self & .434 & .1213 & $12.817 * * *$ & Self & .128 & .1210 & 1.127 \\
\hline Automatic & .133 & .1051 & 1.604 & Automatic & .145 & .1088 & 1.765 \\
\hline External & -.071 & .0708 & .996 & External & .112 & .0674 & 2.772 \\
\hline \multicolumn{4}{|l|}{ Schizotypal } & \multicolumn{4}{|l|}{ Dependent } \\
\hline Cognitive & .103 & .0625 & 2.693 & Cognitive & -.030 & .0492 & .368 \\
\hline Affective & -.048 & .0674 & .502 & Affective & .119 & .0637 & 3.496 \\
\hline Others & -.144 & .0725 & $3.969 *$ & Others & .166 & .0572 & $8.368 * *$ \\
\hline Self & .379 & .1274 & $8.837 * *$ & Self & .206 & .0985 & $4.386^{*}$ \\
\hline Automatic & .252 & .1161 & $4.708^{*}$ & Automatic & -.003 & .0924 & .001 \\
\hline External & .023 & .0730 & .103 & External & .072 & .0578 & 1.562 \\
\hline \multicolumn{4}{|l|}{ Antisocial } & \multicolumn{4}{|l|}{ Avoidant } \\
\hline Cognitive & -.082 & .0622 & 1.755 & Cognitive & .001 & .0476 & .000 \\
\hline Affective & .346 & .0842 & $16.934 * * *$ & Affective & -.185 & .0553 & $11.186^{* * *}$ \\
\hline Others & -.106 & .0744 & 2.020 & Others & .104 & .0549 & 3.598 \\
\hline Self & .089 & .1322 & .453 & Self & .446 & .0949 & $22.033 * * *$ \\
\hline Automatic & .384 & .1239 & $9.582 * *$ & Automatic & .022 & .0881 & .064 \\
\hline External & .047 & .0757 & .384 & External & .062 & .0562 & 1.234 \\
\hline \multicolumn{4}{|l|}{ Borderline } & \multicolumn{4}{|c|}{ Obsessive Compulsive } \\
\hline Cognitive & .013 & .0370 & .119 & Cognitive & .236 & .0655 & $12.946 * * *$ \\
\hline Affective & .372 & .0510 & $53.241 * * *$ & Affective & -.148 & .0698 & 4.467 \\
\hline Others & .127 & .0433 & $8.607 * *$ & Others & -.106 & .0715 & 2.212 \\
\hline Self & .053 & .0748 & .507 & Self & .253 & .1186 & $4.566^{*}$ \\
\hline Automatic & .167 & .0705 & $5.611 *$ & Automatic & -.169 & .1074 & 2.478 \\
\hline External & .049 & .0427 & 1.313 & External & .122 & .0708 & 2.955 \\
\hline
\end{tabular}

SE, standard error; $* \mathrm{P} \leq 0.05 ; * * \mathrm{P} \leq 0.01 ; * * * \mathrm{P} \leq 0.001$. 
manifestations (which are most accurately diagnosed by the PDM-2; Lingiardi \& McWilliams, 2017). Moreover, we must consider that the narcissistic patients described here are patients treated in psychotherapy, a condition related to a specific help request by patients and an asymmetric relationship, in which the attachment system of patients is stimulated with a consequential increase in arousal; this may lead to the expression of problematics in the emotional regulation in narcissistic patients, especially when they have to face feelings of shame and inadequacy. Contrary to our expectations, antisocial PD was also characterized by an affective imbalance. This data is somehow in contrast with part of the clinical literature on mentalization and PDs (Bateman, Bolton, \& Fonagy, 2013) but is in line with empirical studies which have found higher levels of anger in patients with this disorder (Yavuz et al., 2016). For the future it will be necessary to further investigate this issue, and also possibile differences in the emotional responses between patients with antisocial PD and psychopathic traits.

The present study has several limitations. The first is represented by the fact that the assessment of mentalization, and of patients' personality, has been made exclusively using one perspective, that of clinicians, which presents some limits to the interpretation of our results. For example, clinicians' perceptions of the patient's personality could be influenced by the perception of patient mentalization, and vice versa, and/or evaluations may be influenced by clinicians' emotional responses toward the patients. Another concern is related to the possible influence of clinicians' theoretical preferences: Whether we are mapping the construct of mentalization or the clinician's view of the construct is, in fact, a real question.

This limitation (the single-informant assessment perspective) is shared by several studies on mentalization, which were mostly based on the evaluation of a single informant, either the patient (Hausberg et al., 2012; Badoud et al., 2015) or an external rater (Chiesa \& Fonagy, 2014; Semerari et al., 2012). Therefore, we do not doubt that clinicians' evaluations may present some of the aforementioned biases. At the same time, we also believe that different biases may affect the assessment provided by patients, especially if diagnosed with PDs (who may have problems in completing a self-report assessment measure because of their difficulties in self-reflexivity and egosyntonic traits), or by an external rater (who does not experience the patient-therapist interpersonal relationship and may have difficulty recognizing the implicit facets of mentalization, which are an important feature of the construct). In other words, each and every perspective is unique and has its strengths and limitations; in this first stage of validation of the measure, we chose to prefer clinicians as the main informants of our study because it was a clinician-report assessment measure's validity that we wanted to test.

A further limitation, somewhat related to the previous one, is that we did not evaluate convergent validity comparing MIS evaluations with other concurrent measures such as, for example, the RFQ (Fonagy et al., 2016), the RFS, or the MAS (Semerari et al., 2003). This represents a major concern related to this work, which limits the possibility to know if our measure is actually assessing mentalization or different construct(s). Future research should include alternative measures of mentalization (including self-report and observer-rated measures) and related constructs (emotion regulation, empathy) to further evaluate validity of the MIS as a measure of mentalization per se and to clarify the mechanisms by which the various facets of mentalization assessed by the MIS relate to clinical variables.

Without the assessment of convergent or divergent validity, moreover, we actually don't know if what we are mapping is mentalization or the clinicians' theoretical construction of mentalization. This implies that in the future (at the present time we are collecting data to address this issue), we need to confirm, by using these measures, that we have really assessed the construct of mentalization in our study. However, some important factors do partially mitigate concerns that the results simply reflect clinician biases. Previous research has suggested that clinicians tend to make highly reliable and valid judgments if their observations are quantified using psychometrically sophisticated instruments, such as the one used in our study (Blagov et al., 2012; Westen \& Weinberger, 2004).

In the future, according to the interdivisional task force on evidence-based therapy, which encouraged researchers to address the observational perspective (i.e., therapist, patient, observer; Norcross \& Wampold, 2011), it will be important to address this issue using more sophisticated designs, such as round-robin ones, based on consensus among multiple raters and/or the use of a multitrait-multimethod approach (Campbell \& Fiske, 1959; Heppner, Kivlighan, \& Wampold, 1999). Agreement among those lenses would provide a solid sense of established facts, while divergence would hold important implications for construct definition and for clinical practice.

A further limitation is represented by the measure used for the PD diagnosis: In this research, we used a procedure that permitted us to count the different criteria met for each $\mathrm{PD}$, a procedure that has been used successfully in different research studies (Colli, Gentile, Tanzilli, Speranza, \& Lingiardi, 2016; Colli, Tanzilli, Dimaggio, \& Lingiardi, 2013; Westen, Shedler, Bradley, \& DeFife, 2011). However, for future research, it will be useful to use more sophisticated and reliable measures for the assessment of personality pathology.

\section{Conclusions}

From the perspective of clinical practice, the assessment measure we presented here can help clinicians in recognizing the specific dimensions that the patient will 
manifest as problematics: for example, a patient manifesting significant imbalances toward the others dimension of mentalization will suggest to the clinician the necessity to focus the therapeutic work on the opposite dimension of mentalization, that is, the self, in order to counterbalance the mental state of the patient. In other words, this measure provides a multidimensional assessment of the constructs that permits obtaining a specific profile of the more damaged dimensions of mentalization of the patient. Therefore, the evaluation of the treatment outcome can be more specific and focused on the core problems in the facets of mentalization. From our point of view, a mentalization assessment measure should be able to describe the different facets of this construct while at the same time being quite economical and clinician friendly. The clinician report that we presented here seems to be a good compromise between complexity and convenience, and may represent a clinically useful tool for the assessment of patients' mentalizing capacity. Moreover, providing an assessment which is specifically focused on the problematics in the different facets of mentalization (and not on a single global score) may help clinicians in different ways, for example at tailoring the interventions with a focus on the imbalances manifested by the patient and monitoring throughout the therapeutic process the changes in each facet of mentalization.

\section{References}

Allen, J.G., Fonagy, P., \& Bateman, A.W. (2008). Mentalizing in clinical practice. Washington, DC: American Psychiatric Publishing.

American Psychiatric Association - APA (2000). Diagnostic and statistical manual of mental disorders (4th ed., text revision) Arlington, VA: American Psychiatric Publishing.

American Psychiatric Association - APA (2013). Diagnostic and statistical manual of mental disorders (5th ed.) Arlington, VA: American Psychiatric Publishing.

Antonsen, B.T., Johansen, M.S., Rø, F.G., Kvarstein, E.H., \& Wilberg, T. (2016). Is reflective functioning associated with clinical symptoms and long-term course in patients with personality disorders? Comprehensive Psychiatry,64, 46-48. doi:10.1016/j.comppsych.2015.05.016

Auerbach, J.S., \& Blatt, S.J. (1996). Self representation in severe psychopathology: The role of reflective self-awareness. Psychoanalytic Psychology, 13(3), 297-341. doi:10.1037/ h0079659

Badoud, D., Luyten, P., Fonseca-Pedrero, E., Eliez, S., Fonagy, P., \& Debbané, M. (2015). The French version of the Reflective Functioning Questionnaire: Validity data for the adolescents and adults and its association with non-suicidal self-injury. PLOSOne, 10(12). doi:10.1371/journal.pone. 0145892

Bateman, A.W., Bolton, R., \& Fonagy, P. (2013). Antisocial personality disorder: A mentalizing framework. The Journal of Lifelong Learning in Psychoanalysis, XI(2),178-186. doi: 10.1176/appi.focus.11.2.178

Bateman, A.W., \& Fonagy, P. (1999). Effectiveness of partial hospitalization in the treatment of Borderline Personality Disor- der: A randomized controlled trial. American Journal of Psychiatry, 156(10), 1563-1569. doi:10.1176/ajp.156.10.1563

Bateman, A.W., \& Fonagy, P. (2004). Psychotherapy for borderline personality disorder. Mentalization based treatment. Oxford: Oxford University Press.

Bateman, A.W., \& Fonagy, P. (2008). 8-year follow up of patients treated for borderline personality disorder: Mentalizationbased treatment versus treatment as usual. American Journal of Psychiatry, 165, 631-638. doi:10.1176/appi.ajp.2007. 07040636

Bateman, A.W., \& Fonagy, P. (2009). Randomized controlled trial of outpatient mentalization-based treatment versus structured clinical management for borderline personality disorder. American Journal of Psychiatry, 166, 1355-1364. doi:10.1176/appi.ajp.2009.09040539

Bateman, A.W., \& Fonagy, P. (2010). Mentalization based treatment for borderline personality disorder. Word Psychiatry, 9(1), 11-15.

Bateman, A.W., \& Fonagy, P. (2012). Handbook of mentalizing in mental health practice. Arlington, VA: American Psychiatric Publishing.

Betan E., Heim A.K., Zittel Conklin C., \& Westen D. (2005). Countertransference phenomena and personality pathology in clinical practice: An empirical investigation. American Journal of Psychiatry, 162, 890-898.

Blagov, B., Bi, W., Shedler, J., \& Westen, D. (2012). The Shedler-Westen Assessment Procedure (SWAP): Evaluating psychometric questions about its reliability, validity, and fixed score distribution. Assessment, 19(3), 370-382. doi: $10.1177 / 1073191112436667$

Blair, J. (2008). Empathic dysfunction in psychopathy. In C. Sharp, P. Fonagy, \& I. Goodyer (Eds.), Social Cognition and Developmental Psychopathology. Oxford: Oxford University Press.

Blais, M., \& Norman, D. (1997). A psychometric evaluation of the DSM-IV personality disorder criteria. Journal of Personality Disorders, 11, 168-176. doi:10.1521/pedi.1997.11.2.168

Blatt, S.J. (2008). Polarities of experiences: Relatedness and selfdefinition in personality development, psychopathology and the therapeutic process. Washington, DC: American Psychological Association.

Bradley R., Heim A.K., Westen D. (2005). Transference patterns in the psychotherapy of personality disorders: empirical investigation. British Journal of Psychiatry, 186, 342-349.

Byrne, B.M. (2001). Structural equation modeling with AMOS. basic concepts, applications, and programming. 1st Ed. New York, London: Routledge.

Campbell, D.T., \& Fiske, D.W. (1959). Convergent and discriminant validation by the multitrait-multimethod matrix. Psychological Bulletin, 56, 81-105.

Chiesa, M., \& Fonagy, P. (2014). Reflective function as a mediator between childhood adversity, personality disorder and symptom distress. Personality And Mental Health, 8(1), 52-66.

Choi-Kain, L.W., \& Gunderson, J.G. (2008). Mentalization: Ontogeny, assessment and application in the treatment of borderline personality disorder. American Journal of Psychiatry, 165(9), 1127-1135. doi:10.1176/appi.ajp.2008. 07081360

Colli, A., Gentile, D., Tanzilli, A., Speranza, A.M., \& Lingiardi, V. (2016). Therapeutic interventions in the treatment of eating disorders: A naturalistic study. Psychotherapy, 53(2), 152-162. doi:doi: $10.1037 /$ pst0000063

Colli, A., Tanzilli, A., Dimaggio, G., \& Lingiardi, V. (2013). Pa- 
tient personality and therapist response: An empirical investigation. American Journal of Psychiatry, 171, 102-108. doi:10.1176/appi.ajp.2013.13020224

Cronbach, L.J. (1951). Coefficient alpha and the internal structure of tests. Psychometrika, 16(3), 297-334. doi:10.1007/ BF0231055

Dimaggio, G., Procacci, M., Nicolò, G., Popolo, R., Semerari, A., Carcione, A., \& Lysaker, P.H. (2007). Poor metacognition in patients with narcissistic and avoidant personality disorders: Four psychotherapy patients analyzed with the Metacognition Assessment Scale. Clinical Psychology and Psychotherapy, 14(5), 386-401. doi:10.1002/cpp.541

Fonagy, P. (1991). Thinking about thinking: Some clinical and theoretical considerations in the treatment of a borderline patient. International Journal of Psychoanalysis, 72(4), 639-656.

Fonagy, P., \& Bateman, A.W. (2006). Mechanisms of change in mentalization based treatment of BPD. Journal of Clinical Psychology, 62(4), 411-430. doi:10.1002/jclp.20241

Fonagy, P., Bateman, A.W., \& Luyten, P. (2012). Introduction and overview. In A.W. Bateman, \& P. Fonagy (Eds.), Handbook of mentalizing in mental health practice (pp. 3-42). Arlington, VA: American Psychiatric Publishing.

Fonagy, P., Gergely, G., Jurist, E.J., \& Target, M. (2002). Affect regulation, mentalization and the development of the self. New York, NY: Other Press.

Fonagy, P., Leigh, T., Steele, M., Steele, H., Kennedy, R., Mattoon, G., ... Gerber, A. (1996). The relation of attachment status, psychiatric classification, and response to psychotherapy. Journal of Consulting and Clinical Psychology, 64(1), 22-31. doi:10.1037/0022-006X.64.1.22

Fonagy, P., Luyten, P., \& Bateman, A.W. (2015). Mentalization as a treatment target in borderline personality disorder. Personality Disorders: Theory, Research, and Treatment, 6(4), 380-392. doi:10.1037/per0000113

Fonagy, P., Luyten, P., Moulton-Perkins, A., Lee, Y.W., Warren, F., Howard, S., ... Lowyck, B. (2016). Development an validation of a self-report measure of mentalizing: The Reflective Functioning Questionnaire. PLOSOne 11(7). doi:e0158678 doi:10.1371/journal.pone.0158678

Fonagy, P., Steele, H., \& Steele, M. (1991). Maternal representations of attachment during pregnancy predict the organization of infant-mother attachment at one year of age. Child Development, 62(5), 891-905. doi:10.1111/j.1467-8624. 1991.tb01578.x

Fonagy, P., \& Target, M. (1997). Attachment and reflective function: Their role in self-organization. Development and Psychopathology, 9(4), 679-700.

Fonagy, P., \& Target, M. (1998). Mentalization and the changing aims of child psychoanalysis. Psychoanalytic Dialogues: The International Journal of Relational Perspectives, 8(1), 87114. doi:10.1080/10481889809539235

Gullestad, F.S., \& Wilberg, T. (2011). Change in reflective functioning during psychotherapy: a single case study. Psychotherapy Research, 21(1), 97-111. doi:10.1080/10503307. 2010.525759

Ha, C., Sharp, C., Ensink, K., \& Cirino, P.T. (2013). The measurement of reflective function in adolescents with and with our borderline traits. Journal of Adolescence, 36(6), 12151223. doi:10.1016/j.adolescence.2013.09.008

Hausberg, M.C., Schultz, H., Piegler, T., Happach, C.G., Klöppel, M., Brütt A.L., ... Andreas, S. (2012). Is a self-rated instrument appropriate to assess mentalization in patients with men- tal disorders? Development and first validation of the Mentalization Questionnaire (MZQ). Psychotherapy Research, 22(6), 699-709. doi:10.1080/10503307.2012.709325

Heppner, P.P., Kivlighan, D.M., \& Wampold, B.E. (1999). Research design in counseling. Belmont, CA: Wadsworth Publishing.

Hu, L.T., \& Bentler, P. M. (1995). Evaluating model fit. In R. H. Hoyle (Ed.), Structural equation modeling: Concepts, issues, and applications (pp. 76-99). Thousand Oaks, CA, US: Sage Publications, Inc.

Jurist, E. (2005). Mentalized affectivity. Psychoanalytic Psychology, 22(3), 426-444.

Katznelson, H. (2014). Reflective function: A review. Clinical Psychology Review, 34(2), 107-117. doi:10.1016/j.cpr.2013. 12.003

Kline, R.B. (1991). Latent variable path analysis in clinical research: A beginner's tour guide. Journal of Clinical Psychology, 47, 471-484.

Fornell, C., \& Larcker, D. F. (1981). Evaluating structural equation models with unobservable variables and measurement error. Journal of Marketing Research, 18(1), 39-50.

Liljenfors, R., \& Lundh, L.G. (2015). Mentalization and intersubjectivity. Towards a theoretical integration. Psychoanalytic Psychology, 32(1); 36-60. doi:10.1037/a0037129

Lingiardi, V., \& McWilliams, N. (2017). Psychodynamic diagnostic manual. 2nd Ed. New York: Guilford Press.

Lowyck, B., Luyten, P., Vanwalleghe, C., Vermote, R., Mayes, L.C., \& Crowley, M.J. (2016). What's in a face? Mentalizing in borderline personality disorder based on dynamically changing facial expressions. Personality Disorders, 7(1), 7279. doi:10.1037/per0000144

Luyten, P., \& Fonagy, P. (2015). The neurobiology of mentalizing. Personality Disorders: Theory, Research, and Treatment, 6(4), 366-379. doi:10.1037/per0000117

Luyten, P., Fonagy, P., Lowyck, B., \& Vermote, R. (2012). Assessment of mentalization. In A.W. Bateman \& P. Fonagy (Eds.), Handbook of mentalizing in mental health practice (pp. 43-66). Arlington, VA: American Psychiatric Publishing.

Lysaker, P.A., Olesek, K., Buck, K., Leonhardt, B.L., Voss, J., Ringer, J., ... Outcalt, J. (2014). Metacognitive mastery moderates the relationship of alexithymia with cluster $\mathrm{C}$ personality disorder traits in adults with substance abuse disorders. Addictive Behaviors, 39, 558-561. doi:10.1016/j.addbeh. 2013.11.007

Moroni, F., Procacci, M., Pellacchia, G., Semerari, A., Nicolò, G., Carcione, A. ... Colle, L. (2016). Mindreading dysfunction in avoidant personality disorder compared with other personality disorders. Journal of Nervous and Mental Disease, 204(10), 752-757. doi:10.1097/NMD.0000000000000536

Norcross, J.C., \& Wampold, B.E. (2011). Evidence-based therapy relationships: research conclusions and clinical practices. Psychotherapy, 48(1), 98-102. doi: 10.1037/a0022161

Petersen, R., Brakoulias, V., \& Langdon, R. (2016). An experimental investigation of mentalization ability in borderline personality disorder. Comprehensive Psychiatry, 64, 12-21. doi:10.1016/j.comppsych.2015.10.004

Ripoll L.H., Zaki, J., Perez-Rodriguez M.M., Snyder, R., Strike K.S., Boussi A., ... New A.S. (2013). Empathic accuracy and cognition in schizotypal personality disorder. Psychiatry Research, 210, 232-241. doi:10.1016/j.psychres.2013.05.025

Rochat P., \& Striano, T. (1999). Cognitive development in the first year. In Rochat, P. (Ed.) Early Social Cognition (pp. 3-34). Mahwah, NJ: Lawrence Eslbaum Associates. 
Rudden, M., Milrod, B., Target, M., Ackerman, S., \& Graf, E. (2006). Reflective functioning in panic disorder patients: A pilot study. Journal of the American Psychoanalytic Association 54(4), 1339-1343. doi:10.1177/000306510605400 40109

Semerari, A., Carcione, A., Dimaggio, G., Falcone, M., Nicolò, G., Procacci, M., \& Alleva, G. (2003). How to evaluate metacognitive functioning in psychotherapy? The Metacognition Assessment Scale and its applications. Clinical Psychology and Psychotherapy, 10(4), 238-261. doi:10.1002/ cpp.362

Semerari, A., Colle, L., Pellecchia, G., Buccione, I., Carcione, A., Dimaggio, G., ... Pedone, R. (2014). Metacognitive dysfunctions in personality disorders: correlations with disorders severity and personality styles. Journal of Personality Disorders, 28(6), 751-766. doi:10.1521/pedi_2014_28_137

Semerari, A., Colle, L., Pellacchia, G., Carcione, A., Conti, L., Fiore, D. ... Pedone, R. (2015). Personality disorders and mind reading: specific impairments in patients with borderline personality disorder compared to other PDs. Journal of Nervous and Mental Disease, 203(8), 626-631. doi:10.1097/NMD. 0000000000000339

Semerari, A., Cucchi, M., Dimaggio, G., Cavadini, D., Carcione, A., Battelli, V., ... \& Smeraldi, E. (2012). The development of the Metacognition Assessment Interview: Instrument description, factor structure and reliability in a non-clinical sample, Psychiatry Research, 200(2-3), 890-895. doi: 10.1016/ j.psychres.2012.07.015

Shamay-Tsoory, S.G., Aharon-Peretz, J., \& Perry, D. (2009). Two systems for empathy: a double dissociation between emotional and cognitive empathy in inferior frontal gyrus versus ventromedial prefrontal lesions. Brain, 132(3), 617-627. doi:10.1093/brain/awn279
Skårderud, F. (2007). Eating one's words, part II: The embodied mind and reflective function in anorexia nervosa - theory. European Eating Disorders Review, 15(4), 243-252. doi:10. 1002/erv.778

Stevens, J. (2002). Applied multivariate statistics for the social sciences (4th ed.). Mahwah, NJ: Lawrence Erlbaum Associates.

Taubner, S., Hörz, S., Fischer-Kern, M., Doering, S., Buchheim, A., \& Zimmermann, J. (2013). Internal structure of the Reflective Functioning Scale. Psychological Assessment, 25(1), 127-135. doi:10.1037/a0029138

Taubner, S., Kessler, H., Buchheim, A., Kächele, H., \& Staun, L. (2011). The role of mentalization in the psychoanalytic treatment of chronic depression. Psychiatry, 74(1), 49-57. doi:10.1521/psyc.2011.74.1.49

Westen, D., Shedler, J., Bradley, B., \& DeFife, J.A. (2011). An empirically derived taxonomy for personality diagnosis: Bridging science and practice in conceptualizing personality. American Journal of Psychiatry, 269(3), 273-284. doi:10.1176/appi.ajp.2011.11020274

Westen, D., Shedler, J., Durrett, C., Glass, S., \& Martens, A. (2003). Personality diagnoses in adolescence: DSM-IV axis II diagnoses and an empirically derived alternative. American Journal of Psychiatry, 160, 952-966. doi:10.1176/appi.ajp. 160.5.952

Westen, D., \& Weinberger, J. (2004). When clinical description becomes statistical prediction. American Psychologist, 59(7), 595-613. doi:10.1037/0003-066X.59.7.595

Yaghmaie, F. (2009). Content validity and its estimation. Journal of Medical Education, 3(1), 25-27.

Yavuz, K.F., Sahin, O., Ulusoy, S., Ipek, O.U., Kurt, E. (2016). Experiential avoidance, empathy, and anger-related issues in antisocial personality disorder. Turkish Journal of Medial Sciences, 46, 1792-1800. 